\title{
Frequency of cusp of carabelli in maxillary permanent first molars and its association with dental caries in patients visiting Peshawar Dental Hospital, Peshawar.
}

1. BDS, M.Phil (Oral Biology) Assistant Professor Oral Biology Peshawar Dental College Peshawar. 2. BDS, M.Phil (Oral Biology) Assistant Professor Oral Biology Peshawar Dental College Peshawar. 3. BDS,

FCPS (Oral \& Maxillofacial Surgery) Professor

Oral \& Maxillaofacial Surgery

Peshawar Dental College Peshawar.

Correspondence Address:

Dr. Sana Arbab

Department of Oral Biology

Peshawar Dental College Peshawar. sarbab33@yahoo.com

Article received on:

21/05/2020

Accepted for publication:

$03 / 12 / 2020$

\section{Sana Arbab', Munawar Aziz Khattak², Syed Amjad Shah ${ }^{3}$}

ABSTRACT... Objective: To find out the frequency of cusp of Carabelli and its association with dental caries in maxillary permanent first molars in both male and female patients of Peshawar. Study Design: Cross Sectional Study. Setting: OPD of Peshawar Dental Hospital, Peshawar. Period: July 2016 to December 2016. Material \& Methods: A total of 300 patients (125 males and 175 females) were selected through consecutive sampling technique and the number of teeth examined was 600 (two teeth per patient). Age group selected for the patients was from 13 to 30 years. Both the genders having fully erupted maxillary permanent first molars on both sides of the jaw were included in the study and the teeth were examined usinog mouth mirror while the presence of caries in Carabelli groove was checked with the help of dental explorer (probe). Results: Of the total 300 patients, 118 (39.3\%) presented the cusp of Carabelli on maxillary permanent first molars and the number of teeth having the cusp was $192(32 \%)$ out of the total 600 among them. $24.7 \%$ of the patients had cusp present on both right and left MPFM while $10.3 \%$ of patients had CC present only on right maxillary molars and in $4.3 \%$ of patients, it was located on left molars. Gender differentiation of the cusp did not show a statistically significant difference ( $p$-value 0.140 ). The frequency of caries associated with the cusp of Carabelli groove was found to be $17.7 \%$. Out these patients, 8 males (34.7\%) and 15 females $(65.2 \%)$ were affected. $P$ value for this distribution was 0.651 , which shows no statistically significant difference between genders for the presence of caries. Conclusion: The cusp of Carabelli is a common finding on the palatal surface of mesiolingual cusp of maxillary permanent first molars in a hospital-based population of Peshawar with no statistically significant difference between males and females. Caries in cusp of Carabelli groove is a common association with the cusp having no significant difference between genders.

Key words: Cusp of Carabelli, Cusp of Carabelli Groove, Dental Caries, Maxillary Permanent First Molars.

Article Citation: Arbab S, Khattak MA, Shah SA. Frequency of cusp of carabelli in maxillary permanent first molars and its association with dental caries in patients visiting Peshawar Dental Hospital, Peshawar. Professional Med J 2021; 28(8):1101-1106. https://doi.org/10.29309/TPMJ/2021.28.08.4959

\section{INTRODUCTION}

Human teeth may show variations in their morphology in the form of extra cusps, different numbers, and configurations of the roots of teeth and the size and shape of the crowns of teeth. ${ }^{1}$ Accessory cusps are frequently but not usually present in teeth. ${ }^{2}$ Three most commonly noticed extra cusps are: Cusp of Carabelli present on maxillary permanent first molars, Talon cusp located on incisors and Leong's tubercle present on premolars. ${ }^{3}$

The Cusp of Carabelli is a mini cusp or a tubercle considered to be located on the palatal surface of maxillary permanent first molars on the mesiopalatal cusp adjacent to the mesiopalatal line angle. It has got no specific function. ${ }^{4}$ It may or may not at all be seen on maxillary second or third permanent molars or deciduous second maxillary molars. 5,6,7 This accessory cusp was discovered by an Austrian Dentist George Von Carabelli. $8,9,10$

Cusp of Carabelli has been noticed to be expressed in different forms ranging from a small groove to a well-developed cusp..$^{9,11,12}$ This phenomenon was seen in a study conducted in Khyber Pakhtunkhwa in which the most common 
expression of this cusp was a small tubercle present in maxillary permanent first molars while some of the patients possessed a prominent form of the cusp. ${ }^{4}$

The exact cause of development of this cusp is unknown but it is believed to be because of the involvement of both genetic and exogenous factors. ${ }^{2,13}$ It is seen in higher percentages in Europeans (70\%-90\%) than other races (35\%$45 \%$ ) which indicate their ethnic variations. ${ }^{2}$

The cusp of Carabelli is separated from the main cusp by a groove termed as the cusp of Carabelli groove. It is more vulnerable to dental caries because of food impacted in this area. ${ }^{14}$ The prevalence of caries in Carabelli groove according to a study carried out in Saudi Arabia was $23.3 \% .^{15}$

The cusp of Carabelli is a common finding in permanent maxillary first molars as compared to second and third molars and very little work has been done involving local subjects to determine the frequency of cusp of Carabelli \& its associated features. Therefore, it is aimed to collect data regarding this cusp in a group of local subjects and to report the frequency of this cusp in both male and female and to identify its associated presenting features like caries in Carabelli groove. Efforts of researchers in this regard will help the dentists recognize the importance of accessory cusps and to identify their associated complications. Early detection of carious lesion may enable the dental practitioners to use pit and fissure sealants to prevent further spread of caries.

The main purpose of the study was to determine the frequency of cusp of Carabelli in maxillary first permanent molars in patients visiting the Oral Diagnosis department of Peshawar Dental Hospital and caries associated with the cusp of Carabelli.

\section{MATERIAL \& METHODS}

This study was approved by the ethical review committee of Peshawar Medical \& Dental College. Written informed consent was taken from all the participants who were included in the study.

A cross-sectional study was carried out on patients visiting the Oral Diagnosis department of Peshawar Dental Hospital, Peshawar. The sampling technique used in the study was Consecutive Sampling. A total of 300 patients (125 males and 175 females) were recruited in the current study and the number of teeth examined was 600 (two teeth per patient). Age group selected for the patients was from 13 to 30 years. Informed consent was taken from every patient. Both the genders having fully erupted maxillary permanent first molars on both sides of the jaw were included in the study. Exclusion criteria followed was:

- Patients with one or both missing maxillary permanent first molars.

- Presence of any congenital dental disease.

- Direct or indirect restoration or presence of caries-causing gross damage to maxillary permanent first molars.

The data of the patients were recorded on specially designed proforma. Each patient had thorough clinical examination of both the maxillary permanent first molars was done under proper illumination using mouth mirror and dental explorer (probe). The presence of a tubercle or a cuspule on the mesiopalatal surface near the mesiopalatal line angle of maxillary permanent first molars. Apical pressure with the probe was avoided to reduce any discomfort to the patient. The dental explorer was inserted in the cusp of Carabelli groove and was moved laterally in order to detect caries. Sticking of the probe indicated a carious lesion (a distinct brown/black discoloration, non-cavitated, confined to the groove) and the data were recorded accordingly. Apical pressure with the probe was avoided to reduce any discomfort to the patient.

The data was analyzed using computer programmeSPSS version 20. Descriptive statistics including mean age and standard deviations as male to female ratio as well as frequencies and percentages were computed for the cusp of Carabelli and its associated features and caries in the cusp of Carabelli groove and the distribution 
of CC (Cusp of Carabelli) among patients (both males and females) were computed. Pearson's Chi-Square test was used to see the significance of variation from the mean. For $p$-value to be considered significant, its value $\leq 0.05$ was set.

\section{RESULTS}

A total of 300 patients $(\mathrm{N}=300)$ were included in the current study of which there were 125 males $(41.7 \%)$ and 175 females (58.3\%) (Figure-1). The number of teeth examined was $2 \times 300=600$ $(n=600)$ as two teeth were examined per patient according to the inclusion criteria. The total number of maxillary permanent first molars examined in males was 250 and in females, the number of teeth was 350 . The age group selected was 1330 years with a mean age of $22.46 \pm 5.1$ years of the total 300 patients, 118 (39.3\%) presented the cusp of Carabelli on MPFM (Maxillary permanent first molars) and the number of teeth having the cusp was 192 (32\%) out of the total $600.24 .7 \%$ of the patients had cusp present on both right and left MPFM while $10.3 \%$ of patients had CC present only on right maxillary molars and in $4.3 \%$ of patients, it was located on left molars (Figure-2). Gender differentiation of the cusp did not show a statistically significant difference ( $p$-value 0.140 ).

The frequency of caries associated with the cusp of Carabelli groove in patients having CC (Cusp of Carabelli) in MPFM was found to be $17.7 \%$ (23 patients) (Table-I). P value for this distribution was 0.651 , which shows no statistically significant difference between genders for the presence of caries (Table-II). The presence of caries in the cusp of Carabelli groove was detected in those patients who had CC on MPFM (192 in this case). The results showed that 69 MPFM teeth (34.8\%) had a carious lesion associated with CCG (Cusp of Carabelli groove). Out of these 69 teeth, the number of MPFM possessing a carious lesion in CCG in males was found to be 25 (36.2\%) (Number of MPFM on the right side having caries in CCG $=13$, left MPFM having caries in CCG = 12), while in females 44 MPFM (63.7\%) had a carious lesion in CCG.

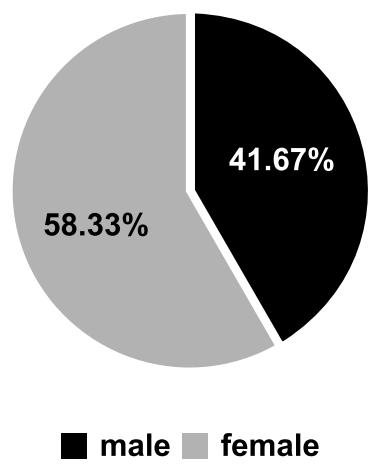

Figure-1. Gender distribution of patients.

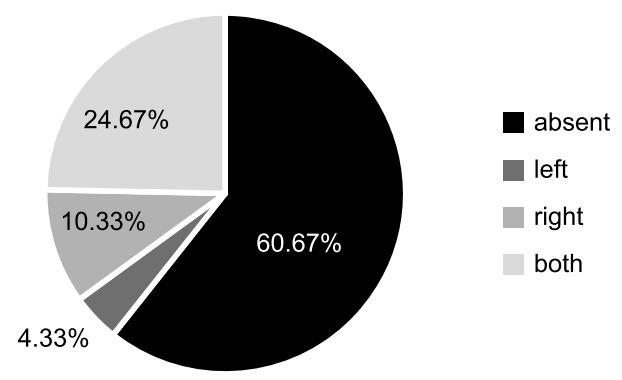

Total number of patients having $C C=39.3 \%$

Figure-2. Frequency of cusp of Carabelli on maxillary first permanent molars.

\begin{tabular}{|c|c|c|}
\hline \multicolumn{2}{|c|}{$\begin{array}{l}\text { Caries in CCG in } \\
\text { Patients Having CC }\end{array}$} & $\begin{array}{l}\text { Number of Patients Having } \\
\text { Caries in CCG N (\%) }\end{array}$ \\
\hline \multicolumn{2}{|l|}{ Absent } & $247(82.3)$ \\
\hline & Right & $23(7.7)$ \\
\hline \multirow[t]{2}{*}{ Present } & Left & $14(4.7)$ \\
\hline & Both & $16(5.3)$ \\
\hline \multicolumn{2}{|l|}{ Total } & $300(100.0)$ \\
\hline
\end{tabular}

\section{DISCUSSION}

The cusp of Carabelli is a common variation found in maxillary permanent first molars. ${ }^{1,2,5,16}$ Various studies have been done on the expression and frequency of cusp of Carabelli in different populations. The current study outlines the frequency of cusp of Carabelli and its association with dental caries in maxillary permanent first molars in a local population of Peshawar. Different studies have reported a wide variation of this cusp in different races demonstrating its ethnic and racial linkage. 


\begin{tabular}{|c|c|c|c|c|c|}
\hline \multirow[t]{2}{*}{ Gender } & \multirow{2}{*}{$\begin{array}{l}\text { Caries in CCG Absent in } \\
\text { Patients Having CC N (\%) }\end{array}$} & & $\begin{array}{l}\text { Caries in CCG Present } \\
\text { in Patients Having CC }\end{array}$ & & \multirow[t]{2}{*}{ Total N (\%) } \\
\hline & & Right N (\%) & Left $\mathbf{N}(\%)$ & Both N (\%) & \\
\hline Female & $142(57.4)$ & $15(65.2)$ & $7(50)$ & $11(68.7)$ & $175(58.3)$ \\
\hline Total & $247(100)$ & $23(100)$ & $14(100)$ & $16(100)$ & $300(100)$ \\
\hline
\end{tabular}

Table-II. Gender-wise distribution of carious lesion in Cusp of Carabelli Groove in MPFM.

$P$ value $=0.651$ measured by Pearson's Chi Square test. $\mathrm{df}=3$. Total number of patients having caries in CCG; Males $=20$ (37.7\%), Females $33(62.2 \%)$.

The presence of such accessory cusps can provide some information regarding a population as their incidence is higher in some populations than others e.g Caucasians exhibit a higher frequency of CC than Mongoloids. ${ }^{17}$

300 subjects (600 teeth) were recruited in the study in which the number of female was higher (175) than male (125). The reason for the larger number of females visiting a dental hospital maybe because they are more concerned about their oral health as compared to male.The age group selected in the study was formed 13 to 30 years. The reason for the selection of this age group was: (1) all the molars are fully erupted, (2) tooth anatomy is well preserved, (3) this is the main age group in which patients frequently visit the dental hospitals for different dental problems, (4) with advancing age teeth may undergo attrition and caries detection becomes difficult in worn off teeth.

The frequency of cusp of Carabelli in the maxillary permanent first molars in the subjects visiting the OPD of Peshawar Dental Hospital was found to be $39.3 \%$ (192 out of 600 teeth), which is in accordance with the study results of Khan et al (2011), ${ }^{4}$ according to whom the frequency of cusp of Carabelli in MPFM was $29.7 \%$ in a hospitalbased population of Khyber Pukhtunkhwa (total sample size of 400 patients). Another study done in Mardan in 2018 showed that Cusp of Carabelli was found in $32 \%$ of the study population on maxillary permanent first molars in patients who visited the out patients department of a teaching hospital in Mardan. The study recruited 100 patients having an age range of 11-55 years. ${ }^{7}$ Smitha et al conducted a study on different ethnic groups residing in Bengaluru including Muslims,
Christians, Hindus and Iranians and reported a higher frequency of cusp of Carabelli on maxillary permanent first molars in Iranian population (58.7\%) as compared to Indians (52.7\%) with an overall frequency of $87.6 \%$ in the surveyed group including all the four ethnic groups. ${ }^{9} \mathrm{~A}$ higher frequency (96\%) of CC in MPFM was found in Iranian subjects aged between 15-49 years, visiting the dental clinics of Isfahan City. ${ }^{10}$ The study results of Dissayanke et al (2004) ${ }^{16}$ revealed the frequency of CC on MPFM to be $38 \%$ which was consistant with the results of the current study. The results of this study were in accordance with those of the current study. Nepalese population showed a frequency of CC in MPFM to be $68.3 \%{ }^{17}$ while Chinese population displayed a prevalence rate of $50.4 \% .^{19} \mathrm{~A}$ frequency of $41.7 \%$ was observed in patients having CC in MPFM in a study conducted by Saadatullah et al in $2012^{18}$ on Abha secondary schoolboys aged between 15-20 years having a sample size of 917 students. A number of researchers included maxillary permanent second molars and maxillary deciduous second molars in their studies as well for the observation of CC but they noticed that the cusp of Carabelli was more prevalent in maxillary permanent first molars rather than any other tooth in the mouth. Shethri in $2011^{15}$ reported a frequency of $15 \%$ of CC on maxillary permanent second molars in contrast to $56.2 \%$ frequency on maxillary permanent first molars. Similarly, other researchers like Khan et al $(2011)^{4}$, Subedi et al $(2014)^{17}$, and Kamanathan et al $(2014)^{20}$ also reported a higher frequency of CC on MPFM than Maxillary permanent second molars or maxillary deciduous second molars.

The current study emphasizes the importance of CC in clinical fields of dentistry as well. This 
is shown by the fact that the cusp of Carabelli groove is an important foci for food stagnation and thus bacterial action on impacted food in such groove leads to the formation of a carious lesion. For the detection of a carious lesion in the cusp of Carabelli good, the patients were clinically examined on the dental chair using standard illumination. The carious lesion was observed using a mouth mirror and a dental explorer. The results of the current study showed an overall frequency of caries in Cusp of Carabelli groove in patients having CC on MPFM to be $17.6 \%$ (Out of the total number of 600 MPFM teeth, 192 teeth had CC and out of these 192 MPFM, 69 had caries in CCG). Pearson's Chi-Square test showed no statistically significant difference between males and females for the distribution of caries in the cusp of Carabelli groove as shown by the $p$-value of 0.651 . Shethri in $2011^{15}$ showed the prevalence of caries in CCG to be $16.8 \%$ while Tangade et al $(2011)^{21}$, observed the carious lesion in CCG in 300 patients having an age group of 12-55 years attending the dental camp organized by Dental Public Health Department and reported a frequency of $18.1 \%$ while The results of both of these studies are in concordance with those of the current study. However, both of these studies did not provide any information regarding the relationship between the presence of caries and gender distribution. A study conducted on Indian children with an age group ranging between 3-4 years showed a susceptibility of cusp of Carabelli to caries reporting a frequency of $10.5 \%$ revealing the fact that there is an increased risk of a carious lesion in patients with a positive cusp expression. ${ }^{22}$ The carious lesion was absent in those patients who did not possess CC on MPFM. It means the groove provides a foci for cariogenic bacteria as the cusp renders a physical barrier for tooth brushing and self-cleansing of the area by saliva thus imparting an ideal environment for the carious process to start.

The findings of the present study may be useful for the dental practitioners to identify the carious lesion associated with CCG in those subjects having $\mathrm{CC}$ and to seal it using pit and fissure sealants to prevent further spread of caries.
The limitations of this study include: small sample size; hospital-based single-centered study; the results were based only on intra oral examination of the participants; no radiographs or dental casts were obtained due to ethical issues; various forms/expressions of the cusp of Carabelli were not noted.

\section{CONCLUSION}

Within the limitations of this study, following conclusion can be drawn:

1. The cusp of Carabelli is a common finding in maxillary permanent first molars in a hospitalbased sample of our local population with no statistically significant difference between males and females for the distribution of the cusp.

2. The incidence of a carious lesion in the cusp of Carabelli groove is reported to be $17.6 \%$ (69 out of 192 MPFM teeth having CC).

3. There is no statistically significant difference between males and females for the presence of caries in the cusp of Carabelli groove.

Copyright $\odot 03$ Dec, 2020.

\section{REFERENCES}

1. Madhuram K, Dhanavel C, Naveen V, Anbu R. Corono radicular anomaly in a maxillary first molar - A rare case report. Indian J Dent. 2012 1(1): 41-44.

2. Duttargi AN, Prasad PR, Sreeshyla HS. Accessory cusp: Cusp of Carabelli- A brief review. Indian J Multidiscip Dent. 3(4): 799-801.

3. S. Nagarajan, M.P. Sockalingam, Mahyuddin A, Bilateral accessory central cusp of 2 nd deciduous molar: An unusual occurrence. Arc Orofac Sci. 2009. 4(1): 22-24

4. Khan DB, Khan MA, Khattak M. Prevalence of cusp of Carabelli in permanent teeth in a group from KPK Pakistan. Pak Oral Dental J. 2011 31(2): 409-10.

5. Mavrodisz K, Rozsa N, Boodai M, Soos A, Pap I, Tarjan I. Prevalence of accessory tooth cusp in a contemporary and ancestral Hungarian population. Eur J Orthod. 2007. 29(2): 166-69.

6. Ferreira MA, Haspenhol LC, Capote TSO, Gongalves, $M A$ and Campos JADB. Presence and morphology of the molar tubercle according to dentition, hemi-arch and sex. Int J Morphol 2010. 28(1): 121-25. 
7. Qamar W, Qayum M, Ali S, Idrees S. Frequency and trends of cusp of Carabelli in maxillary first molars of patients visiting dental teaching hospital in Mardan, Pakistan. Pakistan Orthodontic Journal. 2018; 10(1): 27-29.

8. Scheid RC. Woelfl's Dental Anatomy: Its relevance to dentistry 2007. 7th edition. Maryland: Lippincott Williams and Wilkins.

9. Smitha T, Venkatesh D, Veeresh M, Hema KN, Sheethal HS, Vidya MA. The cusp of Carabelli: Frequency, distribution and type in the Bengaluru population. $J$ Oral Maxillofac Pathol. 2018; 22(3): 418-22.

10. Sarpangala M, Devasya A. Occurrence of Cusp of Carabelli in Primary Second Molar Series of three Cases. J Clin Diagn Res. 2017; 11(3): ZR01-ZR02.

11. Dahlberg AA. Analysis of American Indian dentition. Dental Anthropology. 1963. Brothwell DR, editor, Oxford: Pergamon Press. 149-78.

12. Jordan RE, Abrams L, Kraus BS. Kraus' Dental Anatomy and Occlusion 1991, Mosby, Chicago. 2nd edition.

13. Mosharraf R. Prevalence of cusp of Carabelli trait in Iranian adolescents. SRM J Res Dent Sci. 2013. 4(1): 12-15.

14. Kannapan JG, Swaminathan S. A study on the dental morphological variation: Tubercle of Carabelli. Indian J Dent Res. 2001. 12(3): 145-49.
15. Shethri SA. The prevalence of Carabelli cusp on selected Saudi population. J King Saud Univ Sci. 2011. 2(1-2): 13-16.

16. Dissanayake U, Chandrasekera MS, Wikramanayake ER. The prevalence and mode of inheritance of Carabelli trait in the Sinhalese. Ceylon J Med Sci. 2004. 47(1): 7-15.

17. Subedi N, Sah S, Chataut TP, Paudel S, Pradhan A. Prevalence of Carabelli trait in selected Nepalese population. Br J Med Med Res. 2014 7(4): 285-91.

18. Sadatullah S, Odusanya SA, Mustafa A, Razzak PA, Wahab MA, Meer $Z$. The prevalence of fifth cusp (cusp of Carabelli) in the upper molars in Saudi Arabian school students. Int J Morphol. 2012. 30(2): 757-60.

19. King NM, Tsai JSJ, Wong HM. Morphological and numerical characteristics of the southern Chinese dentitions, part II: traits in the permanent dentition. J Open Anthropol. 2010. 3: 71-84.

20. Kamanatham R, Nuvvula S. Expression of Carabelli trait in children from Southern India- a crosssectional study. J Forensic Dent Sci. 2014. 6(1):51-7.

21. Tangade SP, Ravishankar TL, Tirth A, Mathur A, Batra M. Prevalence of Carabelli trait in Garhwali population, Uttarakhand. J Indian Assoc Public Health Dent. 2011. 2011(17): 114-17.

22. Bhavyaa R, Sujitha P, Muthu MS, Kirthiga M. Prevalence of Cusp of Carabelli and its caries susceptibility - an am bidirectional cohort study. Aust Dent J. 2020.

\begin{tabular}{|c|c|c|c|}
\hline \multicolumn{3}{|c}{ AUTHORSHIP } & AND CONTRIBUTION DECLARATION \\
\hline Sr. \# & Author(s) Full Name & \multicolumn{1}{|c|}{ Contribution to the paper } & Author(s) Signature \\
\hline 1 & Sana Arbab & $\begin{array}{l}\text { Conception \& design acquisition } \\
\text { of data. Drafting the work. } \\
\text { Critical Appraisal, Analysis and } \\
\text { interpretation of data. } \\
\text { Final approval of the work to be } \\
\text { published. }\end{array}$ \\
\hline 3 & Syed Amjad Shah & \begin{tabular}{l} 
Munawar Aziz Khattak \\
\hline
\end{tabular} \\
\hline
\end{tabular}

